\title{
Use of pumped-storage hydroelectricity to compensate for the inherent and unavoidable variability of wind energy
}

\author{
Adam Piasecki ${ }^{1, *}$, and Magdalena Krzywda ${ }^{2}$ \\ ${ }^{1}$ AGH University, Department of Economics, Finance, and Environmental Management, 30-067 \\ Cracow, Poland \\ ${ }^{2}$ AGH University, Department of Engineering Management, 30-067 Cracow, Poland
}

\begin{abstract}
This study investigates the benefits of using pumped-storage hydroelectricity (PSH) as an intermediary between wind turbines and power grid. The approach includes a simulation model and the development of PSH potential estimation. The system sizing was done based on 1985-2014. Potential sites for PSH plants were identified for two provinces of Northern Poland. According to the proposed mathematical model, a simulation of wind-powered PSH was performed for the year 2015. From the obtained results we find that the proposed power unit is capable of ensuring dispatchable energy generation.
\end{abstract}

\section{Introduction}

Renewable energy sources (RES) are generally perceived as a viable solution for eliminating greenhouse gas emissions [1], increasing energy security [2], and creating new employment [3], both in manufacturing and in services. However, they usually come with greater initial costs [4], a larger demand on land for energy-harvesting infrastructure (due to the low intensity of available energy per area) and intermittency in energy generation [5]. This last is especially severe in the case of wind and solar energy, hence variable renewable energy (VRE). The aforementioned characteristics vary depending on climate, financial incentives and workforce costs. According to the literature, there are several challenges for which solutions must be found in order to successfully and cost-effectively integrate RES into power grids. For example, Bird et. al. (2013) [6] points out the stochastic nature of some RES, which demands greater flexibility of the power system. This can be realised by adequate resources to enable adjustment to the sudden ramps in power generation from VRE. In reality, conventional power plants must be able to cover energy demand when there is no available energy from VRE. Vice-versa, when the load is low (especially at night) and wind generation might be approaching its nameplate capacity, conventional power plants must be turned down. Recently, issues related to RES integration have been addressed by Jones (2014) [7] who pointed to VRE forecasting solar, [8] wind [9], hydro [10], demand site management (DSM) [11], intercontinental power grids connections [12] and energy storage [13] as

\footnotetext{
*Corresponding author: adm.piasecki@gmail.com
} 
possible solutions enabling greater penetration of RES in the worldwide energy mix. So far, in order to minimise the impact of varying demand on the operation of power plants, excess energy has mainly been stored in the form of gravitational potential energy - pumped-storage hydroelectricity (PSH). According to Papathanassiou and Boulaxis (2006) [14], energy storage is the most promising way to increase wind's share in covering energy demand. Those issues have been investigated by [15] from the perspective of municipal energy consumer and the complmentary wind and solar energy sources coupled with fuel cell. Various configurations of hybrid energy sources has been investigated in following papers (solarwind [16], solar-wind-PSH [17], wind-PSH, solar-PSH, solar-diesel generator [18] and many more) and pointed to the importance of the temporal complementarity of VREs. The concept of the VREs complementarity has been investigated in numerous papers and considered various time and spatial resolutions. Majority of papers focussed on single countries or even individual sites investigating the temporal complementarity on an annual, seasonal and hourly basis $[19,20,21]$. The energy market is organised such that power plants which can generate electricity at the lowest cost are operating around the clock to cover the base load. Other power units' operation is adjusted to the forecasted demand. Forecast errors are compensated for by quickly ramping up or down gas-powered power plants and energy storage. Projections developed by Fraunhofer ISE [4] indicate that, by 2020, electrical energy coming from onshore wind turbines might be cheaper than that obtained from brown coal. Therefore, using energy derived from wind turbines to cover base load may be cost effective, although there is the issue of wind generation reliability and predictability. One way to overcome this encumbrance is to develop very accurate, long-term wind forecasts. Another is to use energy storage to enable the dispatch of wind-generated energy when needed. To the best of our knowledge, the concept of wind-powered PSH hybrid operating as a conventional power plant has only been presented by [22]. Here we explore and develop this idea by introducing a mathematical simulation model. The created model was then used to investigate the behaviour of hybrids in two Northern Poland provinces, namely Pomerania and West Pomerania, which, as of 30.12 .2015 , have $40 \%$ of the wind turbine power installed in Poland - 1637 MW [23]. PSH storage potential was assessed based on the procedure described in the section Methods \& Data; no existing PSH projects were considered. The aim of this paper was to answer the following research questions:

- Is the estimated potential storage capacity of PSH sites sufficient for the proposed operation of a wind-powered PSH power unit?

- How does PSH capacity affect the energy flow between wind parks and the power grid?

\section{Methods}

\subsection{PSH: potential estimation}

Potential sites for PSH projects were determined based on: the numerical terrain model DTED 2 (Digital Terrain Elevation Data) retrieved from army topography maps of scale 1:50,000; LIDAR (Light Detection and Ranging) data; orthophotomaps; and digital borders of protected areas in Poland. Only lakes of surface area greater than 100 hectares in the Pomorskie Lake Region were selected for further investigation. This initial group was further reduced by eliminating lakes whose water resources were smaller than five million cubic metres. The next step focused on analysing lake surroundings within a 3-kilometre radius from the shoreline, in order to find terrain height differences of greater than 30 metres. If a potential site for an upper reservoir was found, it was assessed for whether its surface is large enough to create a reservoir whose theoretical volume is estimated based on water resources from the lower reservoir. The final constraint, which eliminated several sites, was associated with environmental protection areas which might indispose the creation of a PSH project. Sites fulfilling these criteria are presented in Figure 1. It has been assumed that maximal 
acceptable water-level fluctuations in the lower reservoir cannot exceed 2 metres, which, according to [24], is not uncommon, and is acceptable. Energy storage potential $\mathrm{V}^{\mathrm{GT}}$ for each site has been estimated based on formula (1):

$$
\mathrm{V}^{\mathrm{GT}}=\mathrm{mgh}^{\mathrm{PSH}}
$$

where $\mathrm{m}$ - mass of water stored in the upper reservoir [kg], $\mathrm{g}$ - gravitational acceleration $\left[\frac{\mathrm{m}}{\mathrm{s}^{2}}\right], \mathrm{h}^{\mathrm{PSH}}$ - height difference between lower and upper reservoir $[\mathrm{m}]$.

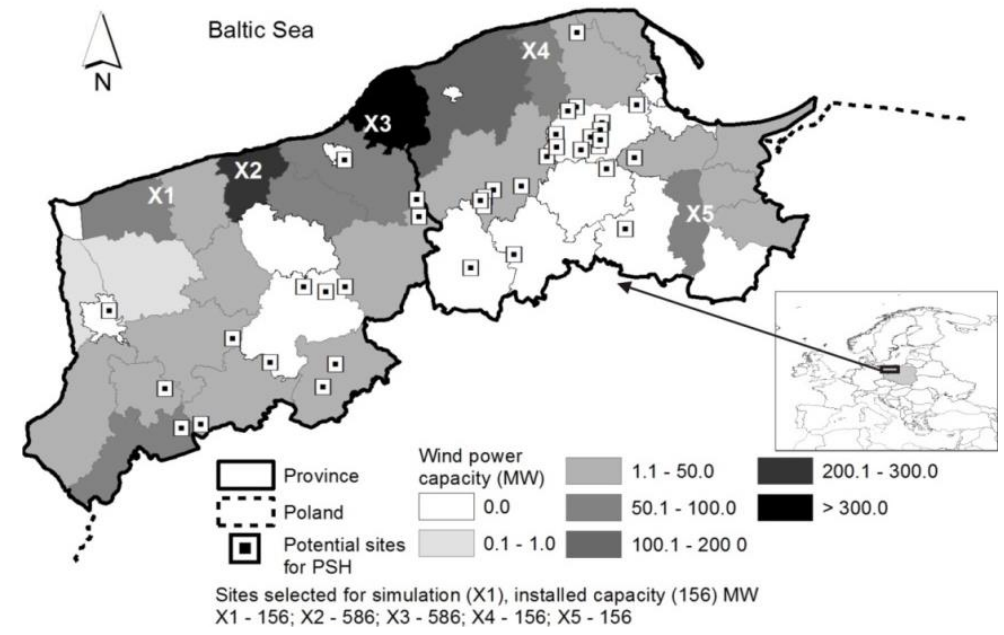

Figure 1. Distribution of power of wind parks installed in West Pomerania (left) and Pomerania districts (data source: URE, 2015), along with potential sites for new PSH projects.

\subsection{PSH: simulation model $\&$ operation principle}

A mathematical model is a concise description of a system by means of mathematical concepts and language. Due to the complexity of real systems, simplifications and omission of some inputs are essential. In this study, it has been assumed that all PSH sites' storage potential is summed and treated as a single site. The impact of precipitation and evaporation on the volume of water stored in both reservoirs (mainly the upper one) has been disregarded. The whole concept is based on the assumption that PSH can simultaneously pump water into the upper reservoir and generate electricity by releasing it into the lower reservoir. Therefore, PSH must be equipped with a set of pumping, as well as generating, water turbines. An overview of energy flow for the proposed hybrid energy source is given in Figure 2. In order to determine the volume of energy stored in the upper reservoir and create a schedule for energy generation, one must first calculate an intermediate value, $\mathrm{E}_{\mathrm{j}, \mathrm{i}}^{\mathrm{B} 1}$, based on formula (2):

$$
E_{j, i}^{B 1}=V_{j, i-1}^{G}+\min \left(\eta_{P S H, P} E_{j, i}^{W T} ; E_{m a x}^{P}\right)-\frac{1}{\eta_{P S H, G}} E_{j, i}^{G}
$$

for $\mathrm{j}=1 \ldots \mathrm{m} ; \mathrm{i}=1 \ldots \mathrm{n}$ and $\mathrm{V}_{1,0}^{\mathrm{G}}=\mathrm{V}^{\mathrm{GT}}$, where $\mathrm{V}_{\mathrm{j}, \mathrm{i}}^{\mathrm{G}}$ - energy stored in the upper reservoir $[\mathrm{MWh}], \eta_{\mathrm{PSH}, \mathrm{P}}-\mathrm{PSH}$ efficiency in pumping mode [\%], $\eta_{\mathrm{PSH}, \mathrm{G}}-\mathrm{PSH}$ efficiency in generating mode [\%], $\mathrm{E}_{\max }^{\mathrm{P}}-$ maximal volume of pumped energy per unit of time [MWh], $E_{j, i}^{G}-$ scheduled energy generation $[M W h], E_{j, i}^{W T}-$ energy generated from wind turbines [MWh].

The value of the energy balance $\mathrm{E}_{\mathrm{j}, \mathrm{i}}^{\mathrm{B} 1}$ is then used to determine the value of two auxiliary binary variables $b_{\mathrm{j}, \mathrm{i}}^{1}(3)$ and $\mathrm{b}_{\mathrm{j}, \mathrm{i}}^{2}(4)$ :

$$
\mathrm{b}_{\mathrm{j}, \mathrm{i}}^{1}=\left\{\begin{array}{l}
1, \text { if } \mathrm{E}_{\mathrm{j}, \mathrm{i}}^{\mathrm{B} 1}>0 \\
0 \text { otherwise }
\end{array}\right.
$$




$$
b_{j, i}^{2}=\left\{\begin{array}{c}
1, \text { if } E_{j, i}^{B 1}>V^{G T} \\
0 \text { otherwise }
\end{array}\right.
$$

for $\mathrm{j}=1 \ldots \mathrm{m} ; \mathrm{i}=1 \ldots \mathrm{n}$, where $\mathrm{V}^{\mathrm{GT}}-$ is maximal energy storage capacity of upper reservoir [MWh].

The calculated values of energy balance and binary variables allow the momentary volume of energy stored in the upper reservoir to be computed (5):

$$
V_{j, i}^{G}=b_{j, i}^{1} b_{j, i}^{2} V^{G T}+b_{j, i}^{1}\left(1-b_{j, i}^{2}\right) E_{j, i}^{B 1}
$$

for $\mathrm{j}=1 \ldots \mathrm{m} ; \mathrm{i}=1 \ldots \mathrm{n}$

An important part of the proposed wind-powered PSH is scheduling the generating operation of water turbines $\left(E_{j, i}^{G}\right)$. This is done based on averaged hourly values of wind generation within each month of the period 1985-2014 reduced by the overall efficiency of PSH $\left(\eta_{\mathrm{PSH}, \mathrm{G}} * \eta_{\mathrm{PSH}, \mathrm{P}}=0.81\right)$. Table 1 summarises those values. From the perspective of RES integration into the power grid, it is important to calculate (6) the volume of wind-turbine energy which cannot be stored in the upper reservoir $-\mathrm{E}_{\mathrm{j}, \mathrm{i}}^{\mathrm{S}}$. This unscheduled energy surplus is a disruption to the energy market balance and may sometimes come with an additional cost for the wind park owner, who in such circumstances may turn down wind turbines.

for $\mathrm{j}=1 \ldots \mathrm{m} ; \mathrm{i}=1 \ldots \mathrm{n}$

$$
E_{j, i}^{S}=b_{j, i}^{1} b_{j, i}^{2}\left|E_{j, i}^{B 1}-V^{G T}\right| \frac{1}{\eta_{P S H, G}}
$$

Additionally, in the proposed approach to scheduling energy generation from PSH, the situation may arise where the amount of energy stored in the upper reservoir and the volume of energy coming from wind generation are not sufficient to cover scheduled generation. This, from the perspective of energy market operation, may be perceived as a sudden and unscheduled energy deficit $-E_{j, i}^{D}$. This value can be calculated based on formula (7):

$$
E_{j, i}^{D}=\left(1-b_{j, i}^{1}\right)\left(\left(V_{j, i-1}^{G}-\eta_{P S H, P} E_{j, i}^{T W}\right) \eta_{P S H, G}-E_{j, i}^{G}\right)
$$

for $\mathrm{j}=2 \ldots \mathrm{m} ; \mathrm{i}=1 \ldots \mathrm{n} \cup \mathrm{j}=1 ; \mathrm{i}=2 \ldots \mathrm{n}$. The initial volume of energy stored in the upper reservoir is $\mathrm{V}_{1,0}^{\mathrm{G}}=\mathrm{V}^{\mathrm{GT}}$.

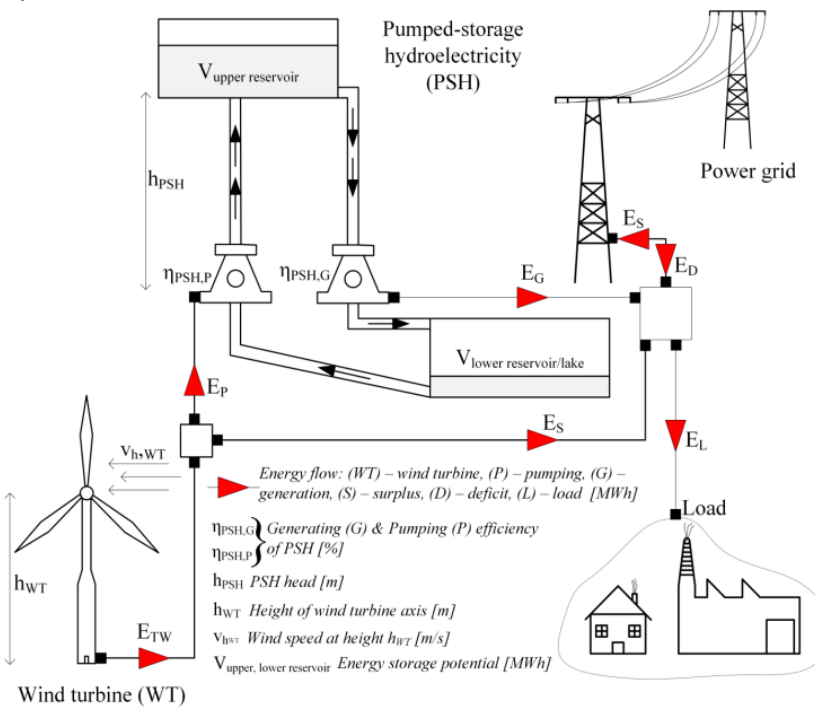

Figure 2. Energy flow outline for proposed wind-PSH power plant.

\subsection{Wind parks: energy yield: location}

Energy yield from wind parks has been calculated based on formula (8). Such an approach has successfully been used inter alia by Notton et. al. (2011) [25]. The power output of the 
wind turbine for wind speed in the range $\mathrm{v}_{\text {cut-in }}$ to $\mathrm{v}_{\text {rated }}$ has been approximated by means of a fourth-degree polynomial which was created for Vestas V90 Gridstreamer [26] power curve.

$$
\mathrm{E}_{\mathrm{j}, \mathrm{i}}^{\mathrm{TW}}=\left\{\begin{array}{c}
0 \text { if } \mathrm{v}_{\mathrm{j}, \mathrm{i}}^{\mathrm{h}_{\mathrm{WT}}}<\mathrm{v}_{\text {cut-in }} \\
\mathrm{N} * \mathrm{P}_{\left(\mathrm{v}_{\mathrm{h}_{\mathrm{WT}}}^{\mathrm{TW}}\right)} * \mathrm{t} \text { if } \mathrm{v}_{\text {cut-in }} \leq \mathrm{v}_{\mathrm{j}, \mathrm{i}}^{\mathrm{h}_{\mathrm{WT}}}<\mathrm{v}_{\text {rated }} \\
\mathrm{N} * \mathrm{P}_{\text {rated }}^{\mathrm{TW}} * \mathrm{t} \text { if } \mathrm{v}_{\text {rated }} \leq \mathrm{v}_{\mathrm{j}, \mathrm{i}}^{\mathrm{h}_{\mathrm{WT}}}<\mathrm{v}_{\text {cut-off }} \\
0 \text { if } \mathrm{v}_{\mathrm{j}, \mathrm{i}}^{\mathrm{h}_{\mathrm{WT}}} \geq \mathrm{v}_{\text {cut-off }}
\end{array}\right.
$$

for $\mathrm{j}=1 \ldots \mathrm{m} ; \mathrm{i}=1 \ldots \mathrm{n}$, where $\mathrm{v}_{\mathrm{j}, \mathrm{i}}^{\mathrm{h}_{\mathrm{WT}}}$ - wind speed at height $\mathrm{h} 2[\mathrm{~m} / \mathrm{s}], \mathrm{v}_{\text {cut-in }}$ - cut-in wind speed $[\mathrm{m} / \mathrm{s}], \mathrm{v}_{\text {cut-off }}$ - cut-off wind speed $[\mathrm{m} / \mathrm{s}], \mathrm{v}_{\text {rated }}$ - wind speed at which wind turbine operates at its rated capacity $[\mathrm{m} / \mathrm{s}], \mathrm{P}_{\text {rated }}^{\mathrm{TW}}-$ wind turbine rated capacity $[\mathrm{MW}], \mathrm{P}_{\left(\mathrm{v}_{\mathrm{h}_{\mathrm{WT}}}^{\mathrm{TW}}\right.}-$ fourth degree polynomial approximation of wind turbine power output [MW], N - number of wind turbines, $\mathrm{t}$ - time [1 hour], $\mathrm{E}_{\mathrm{j}, \mathrm{i}}^{\mathrm{TW}}$-wind generation energy output [MWh].

Polish Power Grid Company publishes only aggregated data on wind generation. This is available on an hourly time scale from June 2012 up to one day ago. However, due to the rapid development of the wind energy sector during recent years, it is hard to estimate the impact of varying mean annual wind speed on energy generation. In this paper, an assumption has been made that wind generation will be simulated based on five locations in Pomerania and West Pomerania (see Figure 1) where the highest concentration of wind parks is observed. Hourly wind speed data was obtained from Modern-Era Retrospective Analysis for Research and Applications (MERRA, 2015). Values obtained from simulating Pomerania and West Pomerania wind parks has shown a good correlation with aggregated wind generation as provided by Polish Power Grid Company for 2015. Despite constituting only to $40 \%$ of installed capacity, the correlation on an hourly scale was 0.86 , whereas on a monthly scale it was 0.97 .

\section{Results}

Based on the approach presented in the Methods section, a total of 37 potential sites for new PSH projects have been retrieved. The mean height difference between upper and lower reservoir was estimated to be 44 metres, with maximal equal to 80 metres and minimal 30 metres. Assuming 2-metre water level fluctuations in the lower reservoir to be acceptable, all 37 sites have the potential to store $62.8 \mathrm{GWh}$ of energy. Considering the fact that some sites lay within environmental protection areas, the storage potential is reduced to $35.2 \mathrm{GWh}$. Those values were further used in two investigated scenarios. Hourly wind generation has been simulated based on five selected locations (see Figure 1) for the years 1985-2015. For those years, the installed capacity in wind turbines was equal to $1640 \mathrm{MW}$. The remaining parameters and model inputs are presented in Table 1.

Over the years 1985-2015, wind turbines generated 95.8 TWh of electrical energy, and the average annual energy yield per $1 \mathrm{MW}$ of installed capacity was $1.9 \mathrm{GWh}$. This results in a capacity factor of $21.5 \%$. The fleet of 820 2-MW wind turbines means that hourly energy generation was 352.7 MWh, with standard deviation of 397.7 MWh. The highest average hourly energy generation was observed in December, and amounted to 556.9 MWh. The lowest was in July, and comprised $36 \%$ of that from December. Assuming an energygeneration schedule for each month as presented in Table 1, a simulation of the proposed power unit was performed for the year 2015. The generation schedule assumed that PSH should generate a total of $2.5 \mathrm{TWh}$ - the mean hourly value varies depending on month. 
Table 1. Simulation model input parameters and their values.

\begin{tabular}{|c|c|c|c|c|c|}
\hline Parameter & Value & Unit & Parameter & Value & Unit \\
\hline $\mathrm{n}$ & $1 \ldots 24$ & - & $E_{\max }^{P}$ & $\mathrm{~N}^{*} P_{\text {rated }}^{T W}{ }^{*} \mathrm{~h}$ & $\mathrm{MWh}$ \\
\hline $\mathrm{m}$ & $1 \ldots 11322$ & - & $E_{\max }^{G}$ & $\mathrm{~N}^{*} P_{\text {rated }}^{T W} * 1 \mathrm{~h}$ & $\mathrm{MWh}$ \\
\hline$v_{\text {rated }}$ & 12 & $\mathrm{~m} / \mathrm{s}$ & $V_{G T}$ & 62.8 and 35.2 & $\mathrm{GWh}$ \\
\hline$v_{\text {cut }- \text { in }}$ & 4 & $\mathrm{~m} / \mathrm{s}$ & $P_{\text {rated }}^{T W}$ & 2 & $\mathrm{MW}$ \\
\hline$v_{\text {cut }- \text { off }}$ & 25 & $\mathrm{~m} / \mathrm{s}$ & $\mathrm{N}$ & 820 & - \\
\hline$\eta_{P S H, P}$ & 90 & $\%$ & $\eta_{P S H, P}$ & 90 & $\%$ \\
\hline \multicolumn{7}{|c|}{ Hourly energy generation from wind turbines $1984-2014[\mathrm{MWh}]$} \\
\hline Month & Mean & $E_{j, i}^{G}$ & Month & Mean & $E_{j, i}^{G}$ \\
\hline January & 556.1 & 450.4 & July & 202.0 & 163.6 \\
\hline February & 514.5 & 416.7 & August & 204.6 & 165.7 \\
\hline March & 429.3 & 347.7 & September & 306.9 & 248.6 \\
\hline April & 284.6 & 230.5 & October & 391.6 & 317.2 \\
\hline May & 208.7 & 169.0 & November & 418.7 & 339.2 \\
\hline June & 209.3 & 169.5 & December & 514.9 & 417.1 \\
\hline
\end{tabular}

For both upper reservoir capacity scenarios, wind turbines generated 3.49 TWh of electrical energy. Clearly, in the case of this year there is a possible energy excess of almost $1 \mathrm{TWh}$. However, due to the constrained capacity of the upper reservoir and the fixed schedule, an energy deficit may even occur. In the scenario assuming $\mathrm{V}^{\mathrm{GT}}=62.8 \mathrm{GWh}$, the observed energy surplus amounted to $619 \mathrm{GWh}$, whereas the energy deficit was almost three times smaller, being as little as $218 \mathrm{GWh}$. In consequence, the actual energy generated by PSH was $2.28 \mathrm{TWh}$, which was $9 \%$ smaller than scheduled. Decreasing the upper reservoir capacity to $\mathrm{V}^{\mathrm{GT}}=35.2 \mathrm{GWh}$ increased the energy surplus by $15 \%$ to $714 \mathrm{GWh}$, and the energy deficit by $30 \%$ to $284 \mathrm{GWh}$, while decreasing actual energy generation from PSH to $2.21 \mathrm{TWh}$. Energy generated from PSH in the second scenario is $12 \%$ smaller than scheduled, but only $3 \%$ smaller than that of the scenario with the greater upper reservoir. The presented results imply that a change in upper reservoir storage potential from $62.8 \mathrm{GWh}$ to $35.2 \mathrm{GWh}$ has a relatively small impact on scheduled generation (see Figures 3 and 4 to compare the energy generation patterns in January 2015). However, the fixed, inflexible generation schedule based on historical data leads to significant energy surpluses and unrealised energy generation (energy deficit). Despite the obvious drawbacks of the applied energy generation schedule (which was not the main issue of this paper), using PSH as an intermediary between wind turbines and the power grid smoothed the energy yield curve. There exist some cases (as in Fig. 3 and 4) where the scheduled energy generation is not met and follows the energy yield pattern from wind turbines. 


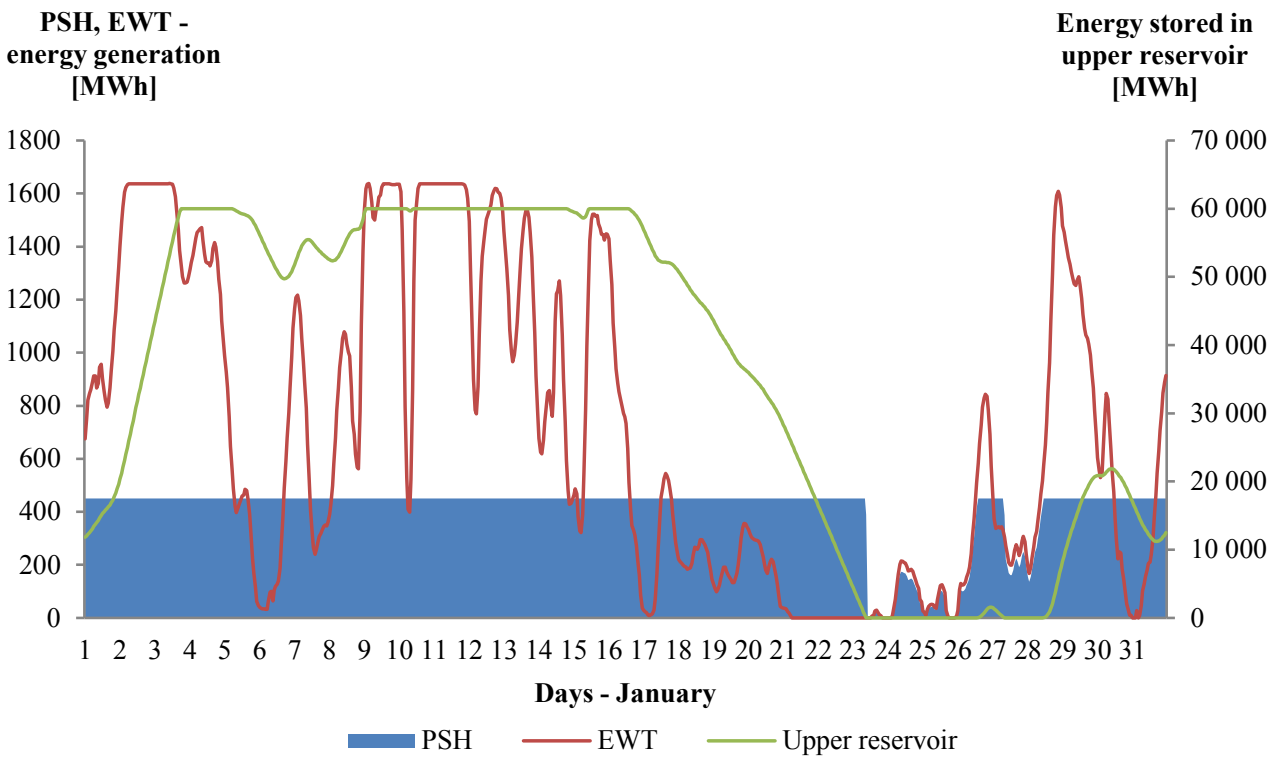

Figure 3. Overview of energy generation of wind-PSH hybrid in January 2015, $V^{G T}=62.8 \mathrm{GWh}$.

PSH, EWT -

energy generation

[MWh]

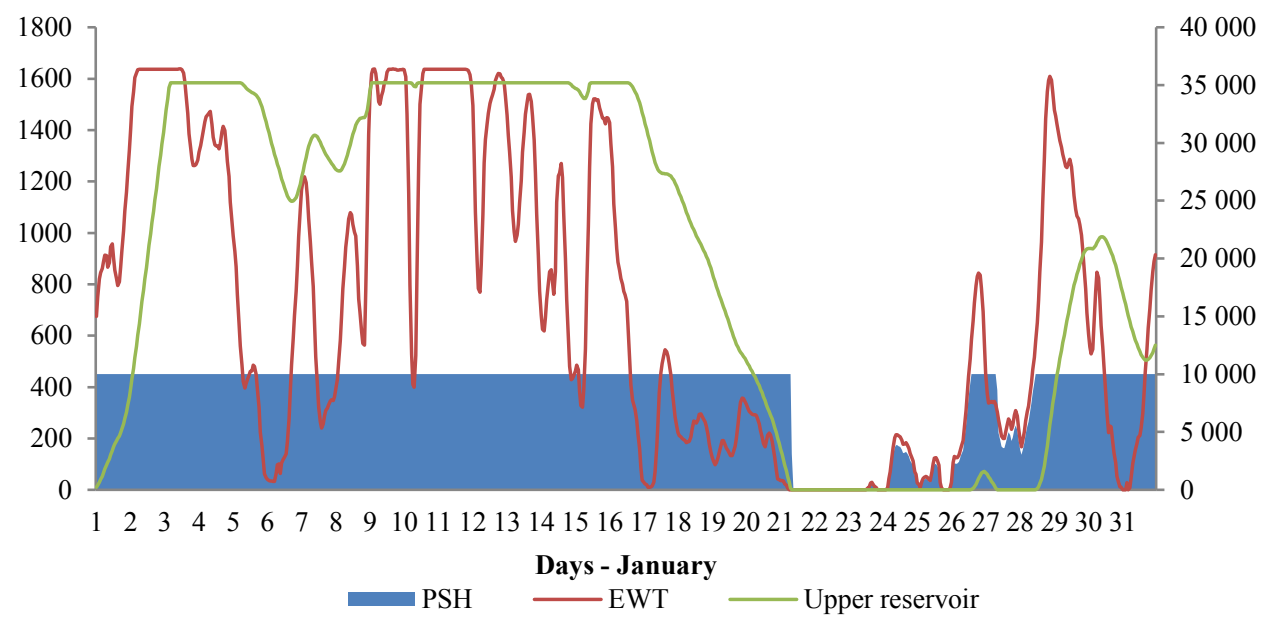

Figure 4. Overview of energy generation of wind-PSH hybrid in January 2015, $V^{G T}=35.2 \mathrm{GWh}$. 


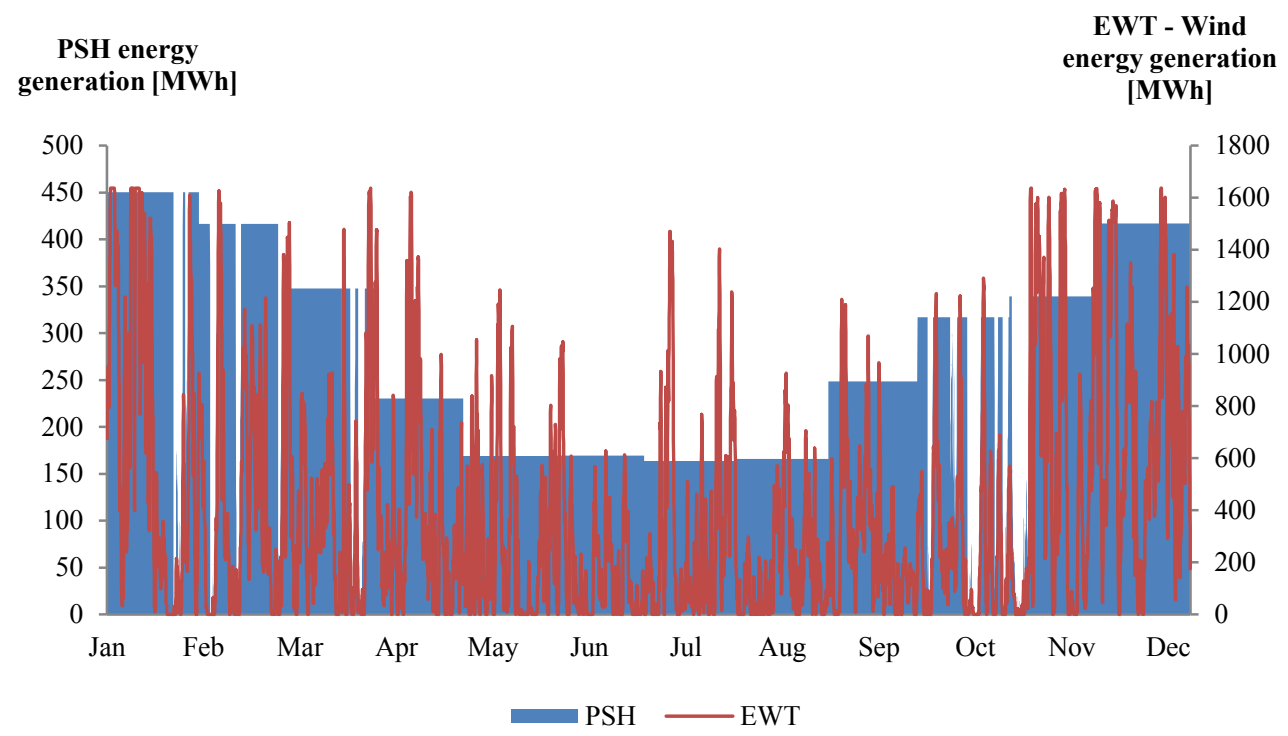

Figure 5. Energy generation from wind turbines and PSH over the year $2015, \mathrm{~V}^{\mathrm{GT}}=62.8 \mathrm{GWh}$.

Of course, amendments can be made to the proposed scheduling approach, for example, by selecting only several crucial hours during which PSH generates electrical energy - this may be evening peak hours, or those when the energy price reaches its highest values, in order to increase the economic viability of proposed solution.

\section{Conclusions}

This paper investigated the use of PSH powered by wind turbines to provide dispatchable and reliable electricity. A mathematical simulation model, a scheduling approach and a site selection method for PSH plants have been presented and tested for two provinces of Northern Poland. Results indicate that West Pomerania and Pomerania have sufficient potential of PSH sites to handle their currently-installed wind turbine capacity. However, future research should thoroughly investigate each site from the perspective of environmental protection. Reducing storage potential from $62.8 \mathrm{GWh}$ to $35.2 \mathrm{GWh}$ leads to greater energy surpluses, but the energy-generation schedule is reduced only by $3 \%$. Further research should investigate whether this can be handled by changing the energy-generation scheduling approach. Results suggest several interesting directions for future research, which should include: economic analysis, consideration of more VRE, input sensitivity analysis and the role of the investigated power source in the energy system.

\section{References}

1. N. L. Panwar, S. C. Kaushik, S. Kothari, Renewable and Sustainable Energy Reviews, 15 (2011)

2. G. E. Francés, J. M. Marín-Quemada, E. S. M. González, Renewable and Sustainable Energy Reviews, 26, 549-559 (2013)

3. T. D. Tsoutsos, Y. A. Stamboulis, Technovation, 25(7), 753-761(2005) 
4. C. Kost, J. N. Mayer, J. Thomsen, N. Hartmann, C. Senkpiel, S. Philipps, ... \& T. Schlegl, Levelized cost of electricity renewable energy technologies. Fraunhofer Institute for Solar Energy Systems ISE (2013)

5. P. Denholm, R. M. Margolis, Energy Policy, 35(9), 4424-4433 (2007)

6. L. Bird, M. Milligan, D. Lew, Integrating Variable Renewable Energy: Challenges and Solutions. National Renewable Energy Laboratory (2013)

7. L. E. Jones, Renewable energy integration: practical management of variability, uncertainty, and flexibility in power grids. Academic Press (2014)

8. D. Masa-Bote, M. Castillo-Cagigal, E. Matallanas, E. Caamaño-Martín, A. Gutiérrez, F. Monasterio-Huelín, J. Jiménez-Leube, Applied Energy, 125, 103-113 (2014)

9. M. Lei, L. Shiyan, J. Chuanwen, L. Hongling, Z. Yan, Renewable and Sustainable Energy Reviews, 13(4), 915-920 (2009)

10. J. Jurasz, Wdowikowski M., E3S Web of Conferences, 14, 01019, (2017)

11. M. R. Staats, P. D. M. De Boer-Meulman, W. G. J. H. M. van Sark, Experimental determination of demand side management potential of wet appliances in the Netherlands. Sustainable Energy, Grids and Networks (2016)

12. Kies, A., Schyska, B., Viet, D. T., von Bremen, L., Heinemann, D., \& Schramm, S.. Energy Procedia, 125, 207-213 (2017)

13. Kies, A. Journal of Physics: Conference Series (Vol. 977, No. 1, p. 012005). IOP Publishing (2018)

14. S. A. Papathanassiou, N. G. Boulaxis, Renewable energy, 31(4), 457-479 (2006)

15. R. Szczerbowski, B. Ceran, E3S Web of Conferences, 10, 00090 (2016)

16. G. Bekele, B. Palm, Applied Energy, 87(2), 487-495 (2010)

17. T. Ma, H. Yang, L. Lu, J. Peng, Renewable energy, 69, 7-15 (2014)

18. M. Datta, T. Senjyu, A. Yona, T. Funabashi, C. H. Kim, IEEE Transactions on Energy Conversion, 26(2), 559-571 (2011)

19. J. Jurasz, M. Wdowikowski, B. Kaźmierczak, P. Dąbek, E3S Web of Conferences, 22, 00074 (2017)

20. J. Jurasz, A. Piasecki, Acta Energetica, 1(26), 98-106 (2016)

21. J. Widén, N. Carpman, V. Castellucci, D. Lingfors, J. Olauson, F. Remouit, R. Waters, Renewable and Sustainable Energy Reviews, 44, 356-375 (2015)

22. K. Qian, Y. Jiang, Z. Li, Remote Sensing, Environment and Transportation Engineering (RSETE), 406-411 (2011)

23. URE 2015 http://www.ure.gov.pl/uremapoze/mapa.html access 05.02.2016

24. P. E. Hirsch, S. Schillinger, H. Weigt, P. Burkhardt-Holm, PloS one, 9(12), e114889 (2014)

25. G. Notton, S. Diaf, L. Stoyanov, Energy Procedia, 6, 666-677 (2011)

26. VESTAS https://www.vestas.com/ access 10.02.2016 